\title{
Hemiacetal formation from a Schiff base in the presence of dysprosium(III)
}

\author{
Matilde Fondo ${ }^{1}$, Julio Corredoira-Vázquez ${ }^{1, *}$, Ana M. García Deibe ${ }^{1}$ and Jesús \\ Sanmartín-Matalobos ${ }^{1}$ \\ 1 Departamento de Química Inorgánica, Facultade de Química, Universidade de Santiago de Compostela, \\ 15782 Santiago de Compostela. E-mails: matilde.fondo@usc.es; julio_corredoira@hotmail.com; \\ ana.garcia.deibe@usc.es; jesus.sanmartin@usc.es \\ * Correspondence: julio_corredoira@hotmail.com; Tel.: +00-34-881814248 \\ + Presented at the title, place, and date. \\ Received: date; Accepted: date; Published: date
}

\begin{abstract}
The formation of hemiacetals from aldehydes and alcohols is quite well known, as these are usually developed as intermediates in the preparation of acetals from aldehydes or ketones. Nevertheless, as far as we know, the examples of transformation of imines into hemiacetals are very scarce, and this reaction seems to be promoted by coordination to a metal ion. In this work, we describe the partial hydrolysis of a Schiff base, and its subsequent evolution to an hemiacetal donor in the presence of dysprosium(III) in an alcoholic medium. Full characterization of the final product, including single $\mathrm{X}$-ray studies, is reported.
\end{abstract}

Keywords: imine, hemiacetal, dysprosium(III)

\section{Introduction}

The reversible acid-catalyzed reaction of aldehydes with alcohols to form acetals occurs via the hemiacetal intermediate. However, isolation of this intermediate is relatively far difficult compared to that of the corresponding stable acetal, being obtained in very small amounts if it is not stabilized by structural effects [1]. One way of stabilizing hemiacetals may be promoted via coordination of metal ions [1-4]. Accordingly, the synthesis of hemiacetal bound metal complexes is a great challenge for coordination chemistry. As far as we know, there are not many complexes containing hemiacetals as ligands reported up to now. These scarce examples usually contain d-metals but, to the best of our knowledge, no hemiacetal complexes have been described with lanthanoid metal ions. Besides, most of the reported complexes were obtained by conversion of aldehydes, but only one case was reported where the hemiacetal donor comes from an imine ligand [5].

Accordingly the conversion and stabilization of hemiacetals in the presence of metal ions is a research field scarcely explored. We describe herein an unusual example of an hemiacetal ligand generated in situ from an imine donor in the presence of dysprosium(III).

\section{Materials and Methods}

\subsection{Materials and general methods}

All chemical reagents and solvents were purchased from commercial sources and used as received without further purification. Elemental analyses of $\mathrm{C}, \mathrm{H}$ and $\mathrm{N}$ were performed on a FISONS EA 1108 analyzer. Infrared spectra were recorded in the ATR mode on a Varian 670 FT/IR spectrophotometer in the range 4000-500 $\mathrm{cm}^{-1} .{ }^{1} \mathrm{H}$ NMR spectrum of $\mathrm{H}_{2} \mathrm{~L}$ was recorded on a Bruker DPX-250 spectrometer, using DMSO- $\mathrm{d}_{6}$ as solvent.

Single X-ray data for 1 were collected at $100 \mathrm{~K}$ on a Bruker D8 VENTURE PHOTON III-14 diffractometer, employing graphite monochromated Mo-k $\alpha(\lambda=0.71073 \AA)$ radiation. Multi scan 
absorption corrections were applied using SADABS [6]. The structure was solved by standard direct methods, employing SHELXT [7], and then refined by full matrix least-squares techniques on $\mathrm{F}^{2}$, using SHELXL from the program package SHELX 2014 [7]. Powder diffractograms for 1 were recorded with a Philips diffractometer with a control unity type "PW1710", a vertical goniometer type "PW1820/00" and a generator type "Enraf Nonius FR590", operating at $40 \mathrm{kV}$ and $30 \mathrm{~mA}$, using monochromated $\mathrm{Cu}-\mathrm{K} \alpha(\lambda=1.5418 \AA)$ radiation. A scan was performed in the range $2<2 \theta<30^{\circ}$ with $\mathrm{t}=3 \mathrm{~s}$ and $\Delta 2 \theta=0.02^{\circ}$. LeBail refinement was obtained with the aid of HighScore Plus Version 3.0d.

\subsection{Syntheses}

2.2.1. Synthesis of $\mathrm{H}_{2} \mathrm{~L}$. The imine ligand $\mathrm{H}_{2} \mathrm{~L}$ (Scheme 1) was obtained by a variation of a previously described method [8], where the ethanol solvent of the reaction is changed by a mixture of chloroform and ethanol, and the ligand was satisfactorily characterized by elemental analysis, IR and ${ }^{1} \mathrm{H}$ NMR spectroscopy. Yield: $97 \%$. Elemental anal. calcd. for $\mathrm{C}_{19} \mathrm{H}_{15} \mathrm{O}_{2} \mathrm{~N}_{3}$ (317): C 71.92, N 13.25, H 4.73 \%. Found: C 71.70, N 13.21, H $4.95 \%$. IR (ATR, $\left.\tilde{v} / \mathrm{cm}^{-1}\right)$ : 1585 (C=Npy), 1624 (C=Nimine), 3352, $3400(\mathrm{OH}) .{ }^{1} \mathrm{H}$ RMN (DMSO-d6, $\left.250 \mathrm{MHz}, \delta / \mathrm{ppm}\right)$ : 6.94-6.96 (m, 4H), $7.15(\mathrm{t}, 2 \mathrm{H}), 7.35(\mathrm{~d}, 2 \mathrm{H}), 8.11(\mathrm{t}$, $1 \mathrm{H}), 8.51(\mathrm{~d}, 2 \mathrm{H}), 8.81(\mathrm{~s}, 2 \mathrm{H}), 9.13(\mathrm{~s}, 2 \mathrm{H})$.

2.2.2. Synthesis of $\left.\left[\mathrm{Dy}\left(\mathrm{HL}^{\prime}\right)_{2}\right)\right]\left[\mathrm{Dy}(\mathrm{L})\left(\mathrm{Cl}_{2}\right)\right](\mathbf{1})$ : To a solution of $\mathrm{H}_{2} \mathrm{~L}(0.112 \mathrm{~g}, 0.353 \mathrm{mmol})$ in methanol $(23 \mathrm{~mL})$ with $\mathrm{pH}=6.5$, a methanolic solution of $\mathrm{Me}_{4} \mathrm{NOH} 0.5 \mathrm{M}$ was added up to $\mathrm{pH}=7.2$. Then, $\mathrm{DyCl}_{3} \cdot 6 \mathrm{H}_{2} \mathrm{O}(0.133 \mathrm{~g}, 0.353 \mathrm{mmol})$ was incorporated, and the mixture refluxed with stirring for $3 \mathrm{~h}$. During this time, a red solid is formed, which is collected by filtration, and dried in air. Yield: $0.065 \mathrm{~g}$ (30\%). Elemental analysis calcd. for $\mathrm{C}_{47} \mathrm{H}_{39} \mathrm{Dy}_{2} \mathrm{~N}_{7} \mathrm{O}_{8}$ (1225.75): C 46.01, N 7.99, H 3.18 \%. Found: 45.97, N 7.89, H $3.04 \%$. IR (ATR, v\% cm-1): 1539 (C=Npy), 1583 (C=Nimine), 3327 (OH).

Recrystallization of the crude product in methanol/hexane yielded single crystals, suitable for X-ray diffraction studies, of 1. Crystal data (at 100(2) K): monoclinic, $\mathrm{C} 2 / \mathrm{c}, \mathrm{C}_{47} \mathrm{H}_{39} \mathrm{Cl}_{2} \mathrm{Dy}_{2} \mathrm{~N}_{7} \mathrm{O}_{8}$, $\mathrm{MW}=1225.75$, with $a=19.188(4) \AA, b=18.419(4) \AA, c=12.866(3) \AA, \beta=94.679(3) \stackrel{\circ}{\circ}, V=4439.2(16) \AA^{3}$, $\mathrm{Z}=4 ; R_{1}=0.0761$ and $w R_{2}=0.1930(\mathrm{I}>2 \sigma \mathrm{I})$.

\section{Results and discussion}

\subsection{Synthesis and spectroscopic characterisation}

Reaction of $\mathrm{DyCl}_{3} \cdot 6 \mathrm{H}_{2} \mathrm{O}$ with a solution of $\mathrm{H}_{2} \mathrm{~L}$ in methanol, basified with tetramethylammoniun hydroxide up to $\mathrm{pH}=7.2$, leads to the ionic complex $\left.\left[\mathrm{Dy}\left(\mathrm{HL}^{\prime}\right)_{2}\right)\right]\left[\mathrm{Dy}(\mathrm{L})\left(\mathrm{Cl}_{2}\right)\right](\mathbf{1})$ (Scheme 1).

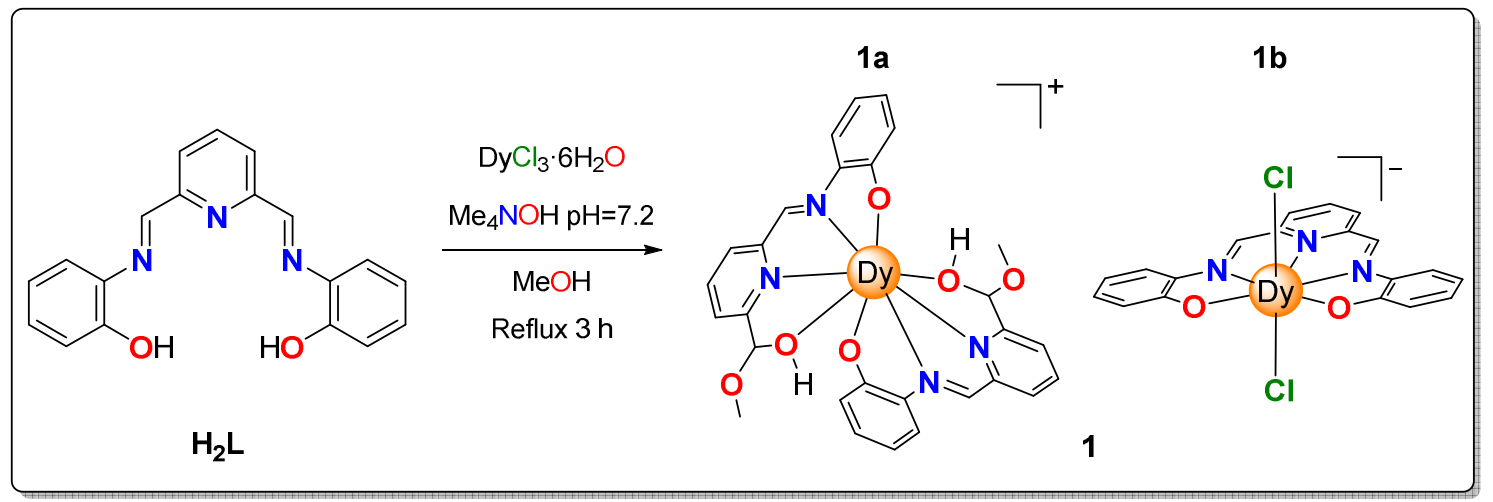

Scheme 1. Reaction scheme for isolation of complex 1

This ionic compound shows that in the $\left.\left[\mathrm{Dy}\left(\mathrm{HL}^{\prime}\right)_{2}\right)\right]^{+}$cation, the dysprosium ion is surrounded by two (HL')- ligands, which derive from the Schiff base L2- (Scheme 1), and that show a hemiacetal functional group. As far as we know, there are not many examples of conversion of imines into hemiacetals, but this reaction, summarized in Scheme 2, seems to be catalyzed by coordination to the 
metal ion [5]. This can readily be inferred from the fact that the Schiff base $\mathrm{H}_{2} \mathrm{~L}$ can be obtained in alcohols with very high yield, and without any evidence of decomposition. Accordingly, the initial step in the formation of the hemiacetal donor should be the partial hydrolysis of the Schiff base, due to the presence of small amounts of water in the reaction medium, followed by a nucleophilic attack of the methanol solvent on the recently formed aldehyde function, all the steps being promoted and stabilized by the dysprosium(III) ion.

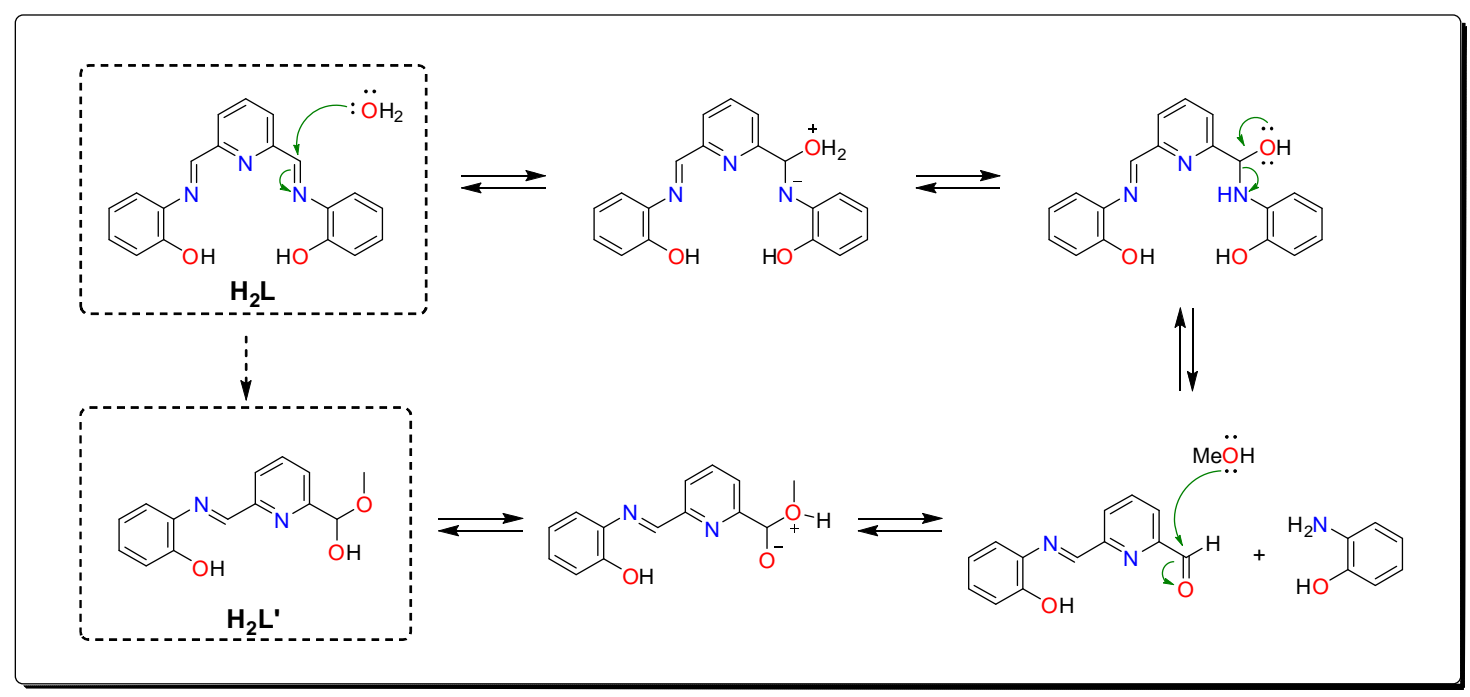

Scheme 2. Proposed mechanism for the formation of hemiacetal from imine functional group

Complex 1 is a red solid, which was unequivocally characterized by microanalysis, IR spectroscopy, single $X$-ray diffraction studies, and powder X-ray diffraction analyses.

The infrared spectrum of 1 shows two intense bands at 1583 and $1539 \mathrm{~cm}^{-1}$, assigned to $v(C=N)$ vibrations of the imine and pyridine moieties, respectively [9], which agree with the presence of at least one imine group. These bands undergo negative shifts of $c a .45 \mathrm{~cm}^{-1}$ respect to the free ligand, indicating that the imine and pyridine nitrogen atoms are coordinated to the metal ion. Besides, the spectrum shows one quite sharp band at $3327 \mathrm{~cm}^{-1}$, in accordance with the presence of the non-deprotonated alcohol function of the hemiacetal group.

\subsection{X-ray difraction studies}

\subsubsection{Single $X$ ray diffraction studies}

Single crystals of $\left.\left[\mathrm{Dy}\left(\mathrm{HL}^{\prime}\right)_{2}\right)\right]\left[\mathrm{Dy}(\mathrm{L})\left(\mathrm{Cl}_{2}\right)\right](\mathbf{1})$ were obtained as detailed above. An ellipsoid diagram for $\mathbf{1}$ is shown in Figure 1 and main distances and angles are recorded in Table 1.
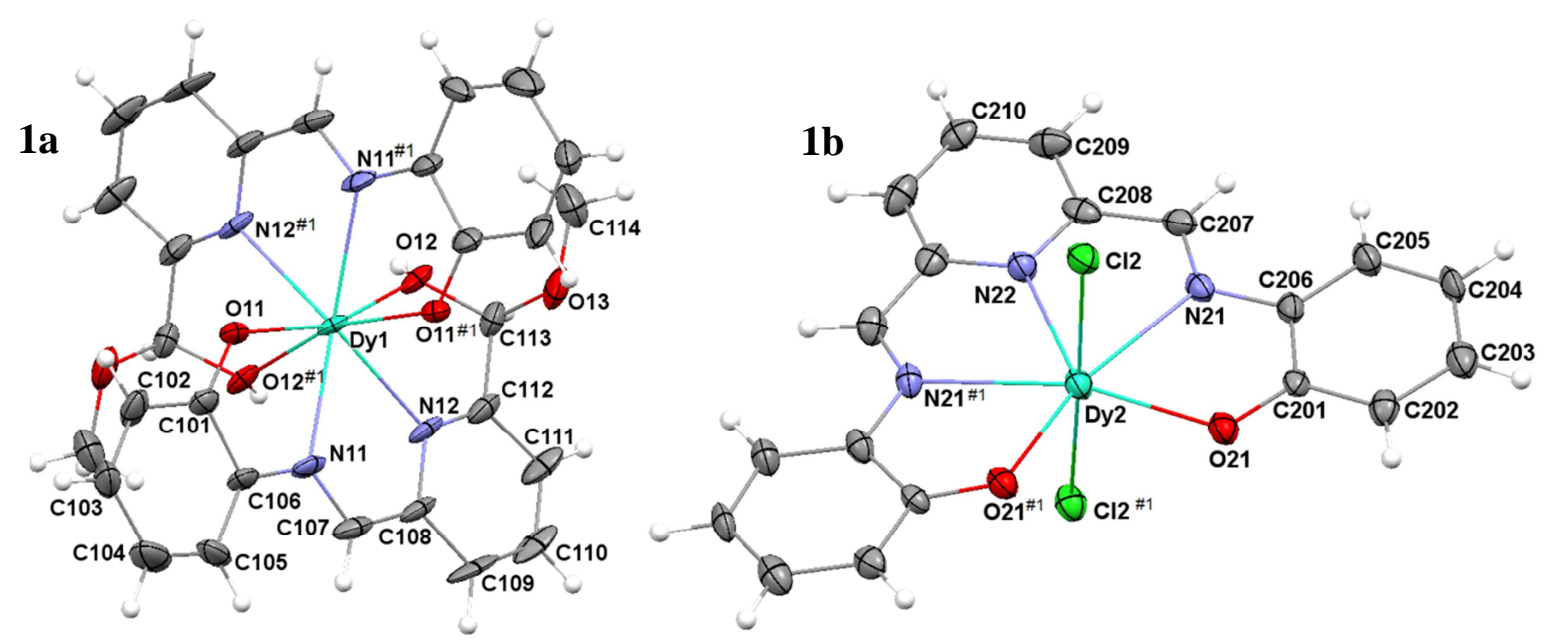

Figure 1. Ellipsoid (30\% probability) diagram for $\mathbf{1}$ : left) cation $\mathbf{1 a}$; right) anion $\mathbf{1 b}$ 
Table 1. Main bond distances ( $(\AA)$ and angles (⿳)丷厂 for 1.

\begin{tabular}{llll}
\hline & $\mathbf{1 a}$ & & $\mathbf{1 b}$ \\
\hline Dy1-O11 & $2.218(9)$ & Dy2-O21 & $2.289(9)$ \\
Dy1-O12 & $2.409(10)$ & Dy2-C12 & $2.613(3)$ \\
Dy1-N11 & $2.451(11)$ & Dy2-N21 & $2.504(10)$ \\
Dy1-N12 & $2.488(10)$ & Dy2-N22 & $2.481(15)$ \\
O12-Dy1-N12 & $64.0(3)$ & N22-Dy2-N21 & $64.9(3)$ \\
O11-Dy1-O12 & $162.5(3)$ & Cl2-Dy2-Cl2 ${ }^{* 1}$ & $176.77(16)$ \\
\hline
\end{tabular}

$\sharp 1:-\mathrm{x}+1, \mathrm{y},-\mathrm{z}+3 / 2$

The crystal structure of $\mathbf{1}$ shows that it is a ionic compound, composed of $\left.\left[\mathrm{Dy}\left(\mathrm{L}^{\prime}\right)_{2}\right)\right]^{+}$cations (1a) and $\left[\mathrm{Dy}(\mathrm{L})\left(\mathrm{Cl}_{2}\right)\right]^{-}$anions $(\mathbf{1 b})$. In the 1a cation (Figure 1), the dysprosium ion is surrounded by two imine-hemiacetal ligands that act as monoanionic $\mathrm{N}_{2} \mathrm{O}_{2}$ donors, linking the metal ion through both nitrogen atoms of the imine and pyridine functions, the deprotonated phenolic oxygen atom, and the protonated alcoholic oxygen atom of the hemiacetal group. Accordingly, the dysprosium ion is octacoordinated in a $\mathrm{N}_{4} \mathrm{O}_{4}$ environment. Calculations of the degree of distortion of the $\mathrm{DyN}_{4} \mathrm{O}_{4}$ core respect to an ideal eight vertex polyhedron with the SHAPE software [10], gives rise to shape measurements closer to triangular dodecahedron, but distorted towards snub diphenoid, as shown in Figure 2. This cation has two chiral centres, the carbon atoms of the hemiacetal group, but both $S, S$ and $R, R$ isomers of $1 \mathbf{a}$ are present in the unit cell in 1:1 ratio, thus giving rise to a racemic mixture.

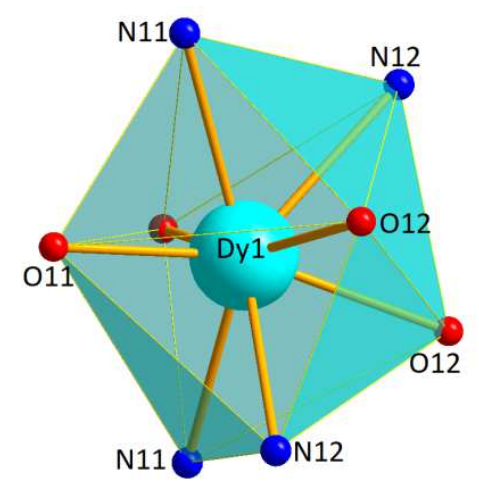

Figure 2. Coordination environment for the Dy(III) ion in 1a, showing the distorted triangular dodecahedron structure.

In the $\mathbf{1 b}$ anion (Figure 1), the bisdeprotonated Schiff base $\mathrm{L}^{2-}$ wraps the dysprosium(III) centre in its $\mathrm{N}_{3} \mathrm{O}_{2}$ pocket. The coordination sphere is completed by two chloride anions, and, accordingly, the dysprosium ion achieves coordination number 7, with slightly distorted pentagonal bipyramid geometry. In this pyramid, the pentadentate donor forms a nearly perfect plane (maximum deviation from any atom from the mean calculated $\mathrm{N}_{3} \mathrm{O}_{2}$ plane of $0.112 \AA$, with the Dy atom in the plane), and the angle $\mathrm{Cl}-\mathrm{Dy}-\mathrm{Cl}$ is $\mathrm{ca}$. $177^{\circ}$.

Besides, this structure is further stabilized by two short hydrogen bonds ( $\mathrm{O} \cdots \mathrm{O}$ distances of $c a 2.5$ $\AA$ ) between the phenolic oxygen atoms of the $\mathbf{1 b}$ anion and the protonated alcoholic functions of the 1a cation, what generates a pseudodinuclear complex, with a Dy ${ }^{\mathrm{III}}$...Dy $\mathrm{y}^{\mathrm{III}}$ distance of ca. $5.5 \AA$ (Figure 3). 


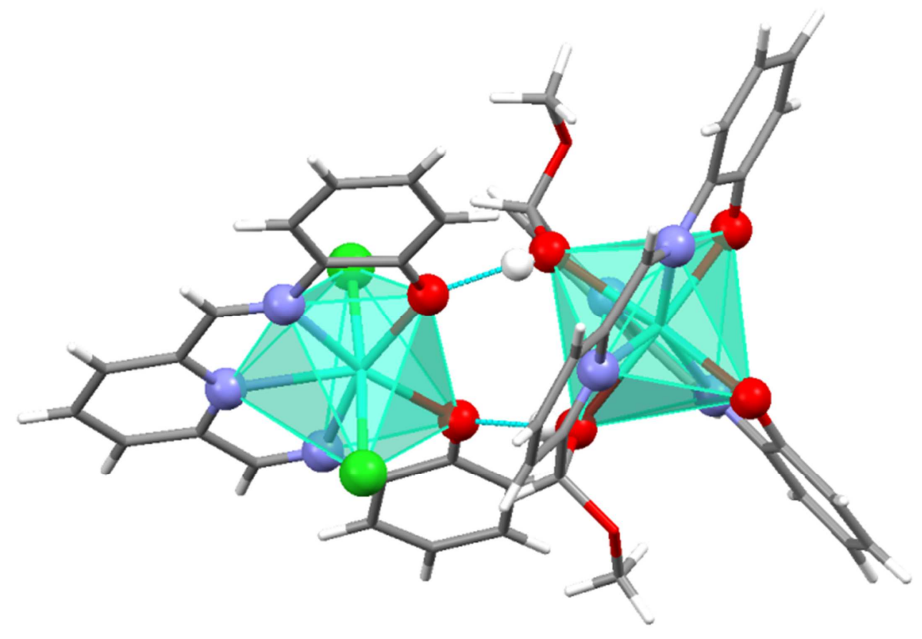

Figure 3. Crystal Structure of $\mathbf{1}$, showing the hydrogen bond between $\mathbf{1 a}$ and $\mathbf{1 b}$.

\subsubsection{Powder $\mathrm{X}$ ray diffraction studies}

Powder X-ray diffractograms for two microscrystalline samples of 1, obtained from two different syntheses, were recorded (Figure 4). This study was done in order to demonstrate that $\mathbf{1}$ is the only product in the solid sample, and not a byproduct generated in the recrystallisation process, and that the experiment is reproducible, and not just the result of serendipity. When these diffractograms were compared with the calculated one using the single X-ray data (Figure 4), it could be concluded that both microcrystalline samples are exactly the same compound, thus demonstrating that the experiment is reproducible, and that they are the same product as the one crystallographically solved.

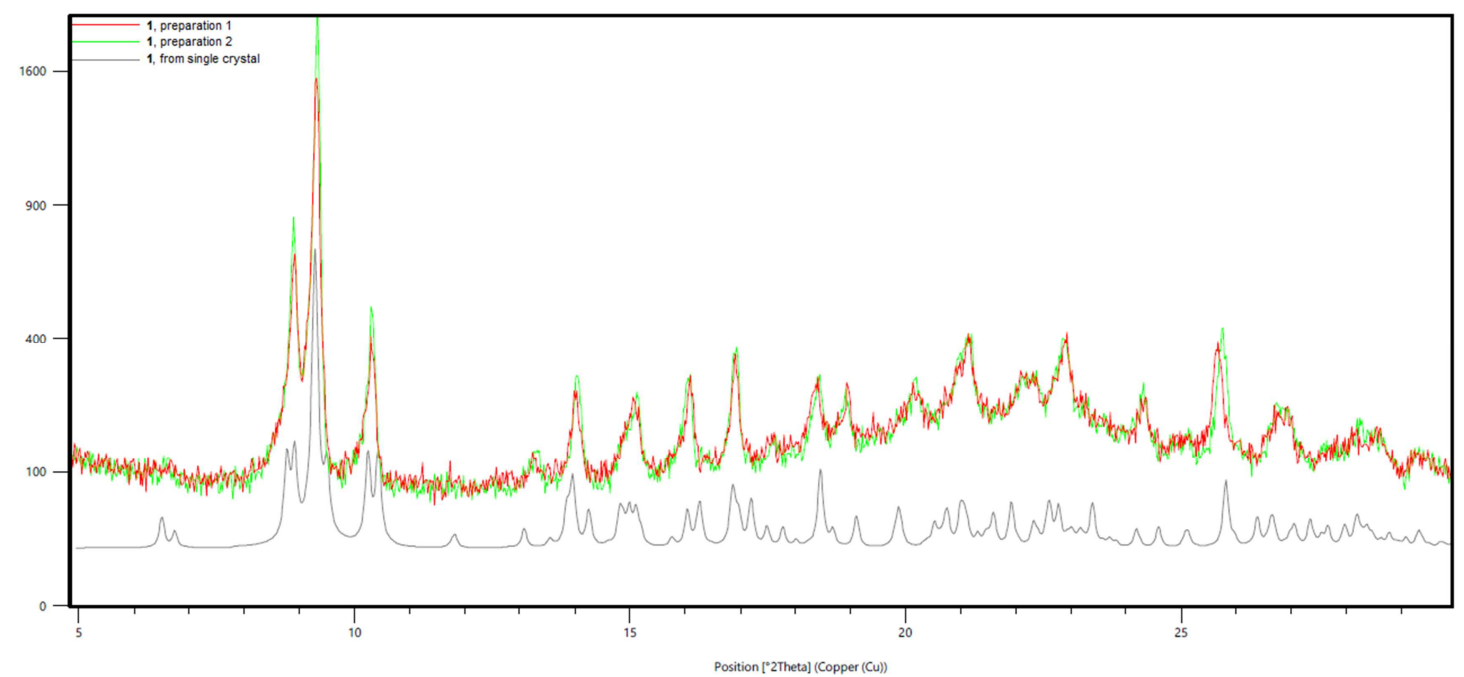

Figure 4. Comparative powder X-ray diffractograms for 3: green and red: experimental diffractograms for two microcrystalline samples obtained from two different syntheses; grey: calculated diffractogram using the data obtained from single $X$-ray diffraction studies.

Accordingly, complex $\mathbf{1}$ is a pure product, obtained as the main product of a reproducible reaction. Thus, it should be noted that, as far as we know, this is the first dysprosium complex with a hemiacetal ligand generated in situ, and crystallographically characterised. 


\section{Conclusions}

This work reports the formation and stabilization of a hemiacetal donor from an imine ligand in the presence of dysprosium(III). Accordingly, this research contributes to increase the scarce number of hemiacetals obtained from imine functions, and the number of metal complexes with hemiacetals as ligands. In addition, complex $\mathbf{1}$, obtained as the pure main product of a reproducible reaction, is the first lanthanoid hemiacetal complex to be crystallographically characterized.

Author Contributions: Conceptualization, Matilde Fondo, Julio Corredoira-Vázquez and Ana M. García-Deibe; methodology, Matilde Fondo and Julio Corredoira-Vázquez; analysis of the data, Matilde Fondo, Julio Corredoira-Vázquez, Jesús Sanmartín-Matalobos and Ana M. García-Deibe; writing-original draft preparation, Matilde Fondo and Julio Corredoira-Vázquez.

Funding: This research was funded by Spanish Ministerio de Innovación, Ciencia y Universidades (PGC2018-102052-B-C21).

Acknowledgments: J. Corredoira-Vázquez acknowledges Xunta de Galicia for his PhD fellowship.

Conflicts of Interest: The authors declare no conflict of interest.

\section{References}

1. Drahonovsky, D.; Lehn, J-M. Hemiacetals in dynamic covalent chemistry: formation, exchange, selection, and modulation processes. J. Org. Chem. 2009, 74, 8428-8432. DOI: 10.1021/jo9009886.

2. Erxleben, A. Copper coordination to the aldehyde and hemiacetal form of 4-bromo-2-[(2-diethylaminoethyl)ethylaminomethyl]-6-formylphenol: synthesis and structure of $\left[\mathrm{Cu}\left(\mathrm{H}_{2} \mathrm{~L}\right)_{2}(\mathrm{X})_{2}\right] \mathrm{X}_{2} \mathrm{nH}_{2} \mathrm{O}\left(\mathrm{X}=\mathrm{NO}_{3}^{-}, \mathrm{ClO}_{4}^{-}\right)$and $\left[\mathrm{Cu}\left(\mathrm{L}^{\prime}\right)\right]_{2} 2 \mathrm{CH}_{3} \mathrm{OH}$. Inorg. Chim. Acta 2009, 362, 839-844. DOI: 10.1016/j.ica.2008.02.016

3. Małecki, J.G.; Zwolinski, P. Synthesis, characterization and molecular structure of $\mathrm{Pd}(\mathrm{II})$ complex containing the methyl-hemiacetal form of isonicotinaldehyde. Polyhedron 2012, 39, 85-90. DOI: 10.1016/j.poly.2012.03.025.

4. Mondal, D; Bhattacharya, K. Synthesis and structural characterization of a hemiacetal and aldehyde bound diiron(III) complex with two different coordination numbers: A product by oxidative cleavage of carbon-nitrogen single bond. Inorg. Chem. Commun. 2017, 84, 109-112. DOI: 10.1016/j.inoche.2017.08.007 and references therein.

5. Barandov, A.; Abram, U. The formation of hemiacetal complexes of rhenium(V) by degradation of a Schiff base. Z. Anorg. Allg. Chem. 2013, 639, 2542-2547. DOI: 10.1002/zaac.201300437.

6. SADABS: Area-Detector Absorption Correction. Siemens Industrial Automation, Inc.: Madison, WI, 1996.

7. Sheldrick, G. M. A short history of SHELX. Acta Crystallogr., Sect. A: Found. Crystallogr. 2008, A64, 112-122. DOI: $10.1107 / S 0108767307043930$.

8. González, A.; Gómez, E.; Cortés-Lozada, A.; Hernández, S.; Ramírez-Apan, T.; Nieto-Camacho, A. Heptacoordinate tin(IV) compounds derived from pyridine Schiff bases: synthesis, characterization, in vitro cytotoxicity, anti-inflammatory and antioxidant activity. Chem. Pharm. Bull. 2009, 57, 5-15. DOI: 10.1248/cpb.57.5.

9. K. Nakamoto, Infrared and Raman Spectra of Inorganic and Coordination Compounds, Ed. John Wiley \& Sons, New York, 1997.

10. (a) M. Llunell, D. Casanova, J. Cirera, J. M. Bofill, P. Alemany, S. Alvarez, M. Pinsky and D. Avnir, D. SHAPE v1.1b, Barcelona, 2005; (b) A. Ruiz-Martínez, D. Casanova and S. Alvarez. Polyhedral Structures with an Odd Number of Vertices: Nine-Coordinate Metal Compounds. Chem. Eur. J., 2008, 14, 1291-1303. DOI: 10.1002/chem.200701137; (c) M. Llunell, D. Casanova, J. Cirera, P. Alemany and S. Alvarez, SHAPE: Program for the stereochemical analysis of molecular fragments by means of continuous shape measures and associated tools, University of Barcelona, Barcelona, Spain, 2010. 